\title{
Patellar dislocation: cylinder cast, splint or brace? An evidence-based review of the literature
}

\author{
Johanna P van Gemert ${ }^{*}$, Lisette M de Vree, Roger A P A Hessels and Menno I Gaakeer
}

\begin{abstract}
Patellar dislocations are a common injury in the emergency department. The conservative management consists of immobilisation with a cylinder cast, posterior splint or removable knee brace. No consensus seems to exist on the most appropriate means of conservative treatment or the duration of immobilisation. Therefore the aims of this review were first to examine whether immobilisation with a cylinder cast causes less redislocation and joint movement restriction than a knee brace or posterior splint and second to compare the redislocation rates after conservative treatment with surgical treatment. A systematic search of Pubmed, Embase and the Cochrane Library was performed. We identified 470 articles. After applying the exclusion and inclusion criteria, only one relevant study comparing conservative treatment with a cylinder cast, brace and posterior splint remained (Mäenpää et al.). In this study, the redislocation frequency per follow-up year was significant higher in the brace group $(0.29 ; p<0.05)$ than in the cylinder cast group (0.12) and the posterior splint group (0.08). The proportion of loss of flexion and extension was the highest in the cylinder cast group and the lowest in the posterior splint group (not significant). The evidence level remained low because of the small study population, difference in duration of immobilisation between groups and use of old braces. Also, 12 studies comparing surgical with conservative treatment were assessed. Only one study reported significantly different redislocation rates after surgical treatment. In conclusion, a posterior splint might be the best therapeutic option because of the low redislocation rates and knee joint restrictions. However, this recommendation is based on only one study with significant limitations. Further investigation with modern braces and standardisation of immobilisation time is needed to find the most appropriate conservative treatment for patellar luxation. Furthermore, there is insufficient evidence to confirm the added value of surgical management.
\end{abstract}

\section{Introduction}

Patients with patellar dislocations are common in the emergency department (incidence 5.8-7 per 100,000 per year) $[1,2]$. After closed reduction, acute primary dislocations can be managed conservatively by immobilisation with a cylinder cast, posterior splint or removable knee brace or by surgical treatment (Figure 1).

The most important complications of primary acute patellar dislocations are recurrence and continued disability [3]. Consequently, it is important to determine the best treatment providing patellar stability and knee function. However, no consensus seems to exist on the most appropriate means of conservative treatment. Also, the immobilisation time has not been standardised. We, as emergency physicians, are seeking the best possible way

\footnotetext{
* Correspondence: anna.vangemert@yahoo.com

Department of Emergency Medicine, University Medical Center Utrecht,
} Utrecht, The Netherlands to treat patients with acute primary patellar dislocation in the emergency department (ED). Therefore the primary aim of this review is to answer the following clinical query: Does immobilisation with a cylinder cast provide less redislocation and joint movement restriction than a knee brace or posterior splint in patients with primary acute patellar dislocation? Secondly we assessed the redislocation rates in surgical versus conservative treatment.

\section{Review}

\section{Methods}

A systematic review of the literature on conservative treatment of patellar dislocations was conducted. A literature search of the PubMed, Embase and the Cochrane Library databases was performed on 17 August 2012. The search terms are shown in Table 1. No limits were imposed. Duplicates were removed using Reference Manager. Studies were eligible for inclusion when the target intervention was a cylinder cast compared with a posterior splint

\section{实}




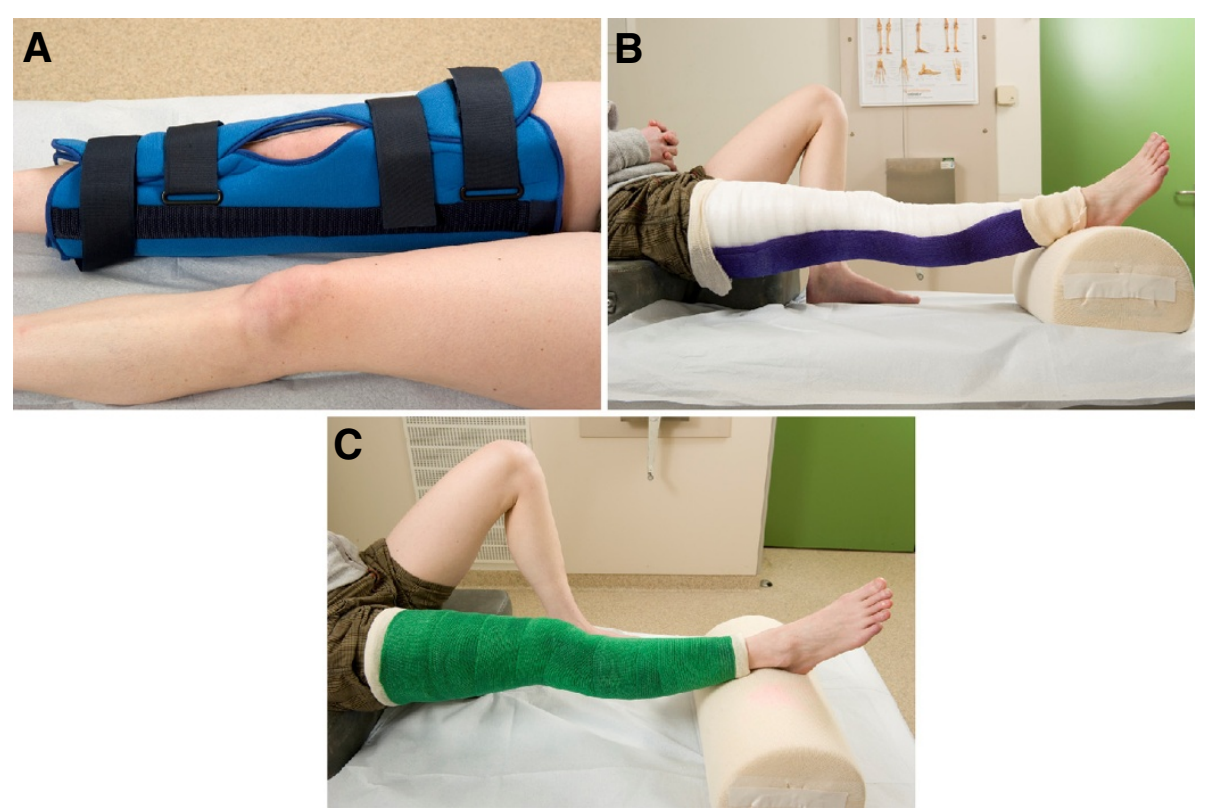

Figure 1 Conservative treatment in acute primary patella dislocation. A: brace. B: posterior splint. C: cylinder cast. Published with permission of the patient.

and a knee brace in patients with primary acute patellar dislocations. These inclusion criteria were used to make a selection based on the title and/or abstracts. Animal studies, case reports with fewer than five cases and studies on patellar fractures were excluded from the review. Independently and in duplicate, two of the authors performed a more thorough selection using the aforementioned exclusion criteria. Bibliographies of all the selected articles were reviewed for additional articles (Figure 2). The primary objectives were to compare redislocation rates and joint movement restrictions after treatment with cylinder casts, posterior splints and knee braces. Secondary objectives were to compare redislocation rates after surgery and conservative treatment. Results were expressed as relative risks (RR) with $95 \%$ confidence intervals (CI95\%) or $p$ values.

\section{Results of the search}

The electronic search identified 470 articles (flowchart: Figure 2). After removing the duplicates, 313 articles remained. Eighteen articles were selected by screening the titles and abstracts of the 313 articles. Of these, studies with a different outcome from the one of interest were excluded $(n=4)$. At the end of the selection process, 15 studies with at least one conservative treatment arm remained (Table 2) [3-17]. No additional articles were found after screening the bibliographies of these articles. Of these 15 studies, 4 did not describe the type of conservative treatment used [4,9-11], 12 compared surgical with conservative treatment $[3-11,13,15,16]$, and 1 compared cylinder casts with tape [14]. These studies could only be used as single-arm studies.

\section{Primary outcome}

Reported redislocation rates ranged between $0-38 \%$ in patients treated with cylinder casts, between $4-53 \%$ in patients treated with splints and $6-54 \%$ in patients treated with braces (Table 2). However, the aforementioned single-arm studies did not provide an answer to our clinical question.

Therefore, only the study of Mäenpää et al. was suitable for answering the clinical question. The results of this study are given in Table 3 . The patient numbers were small in the splint $(n=17)$ and brace $(n=23)$ groups compared to the cylinder cast group $(n=60)$. There were no significant differences in baseline characteristics between groups. The follow-up examination was performed at an average of 13 years later (range 6-26 years). The immobilisation time was shorter in the brace group ( $2 \pm 1$ weeks) than in the splint group ( $3 \pm 2$ weeks) and the cylinder cast

Table 1 Search query as used in pubmed, embase and the cochrane library August 17th, 2012

\begin{tabular}{lll}
\hline & AND & AND \\
\hline $\begin{array}{l}\text { patel* OR } \\
\text { kneecap }\end{array}$ & $\begin{array}{l}\text { luxat* OR subluxat* OR dislocat* OR } \\
\text { displace* OR disarticulat* OR floating }\end{array}$ & $\begin{array}{l}\text { cylinder cast OR gypsum OR plaster OR splint OR immobilisation OR immobilization OR } \\
\text { "conservative treatment" OR brace OR sleeve OR support OR bandage OR orthosis OR } \\
\text { nonoperative }\end{array}$ \\
\hline
\end{tabular}




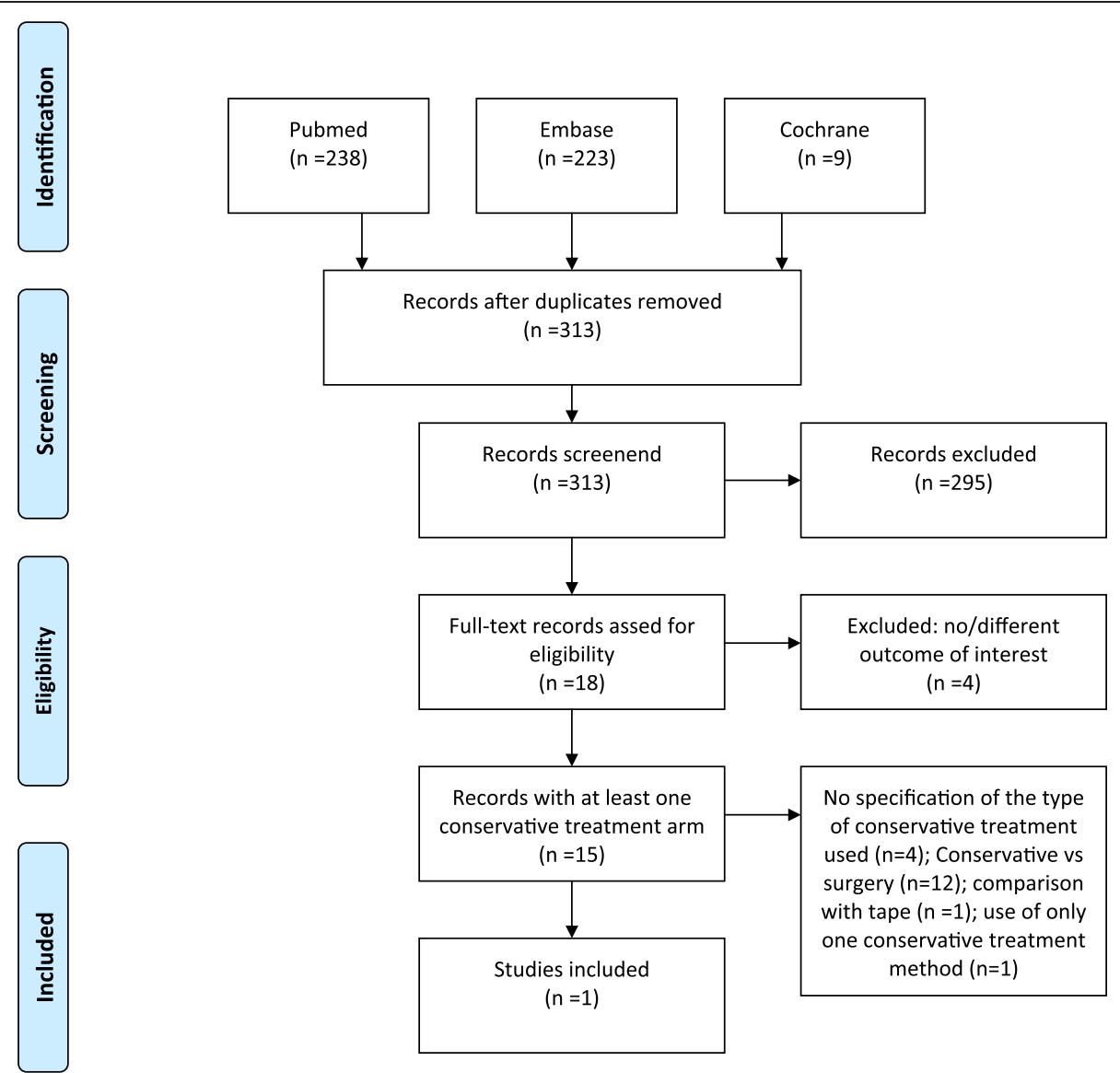

Figure 2 Flow chart review.

group ( $4 \pm 11$ weeks). Redislocation rates ranged from $38 \%$ in the cylinder cast group to $47 \%$ in the posterior splint group to $57 \%$ in the brace group. There were no significant differences among these groups. Furthermore, the redislocation frequencies per follow-up year were significantly higher in the brace group $(0.29 ; P<0.05)$ than in the cylinder cast group (0.12) and the posterior splint group (0.08). There were no significant differences between the loss of extension and flexion between groups. However, in the cylinder cast group the proportion of loss of flexion and extension was the highest [12].

\section{Secondary outcome}

Twelve studies reported redislocation rates after surgery compared to conservative treatment [3-11,13,15,16]. Only one study showed a significantly lower redislocation rate in the surgical group [16]. The other studies did not report a significant difference between surgical and non-surgical management.

\section{Discussion}

The query in the Medline, Embase and Cochrane databases resulted in only one relevant article (Mäenpää et al.).
Mäenpää et al. recommend using a posterior splint for acute primary patella dislocation because of the low knee joint restriction and low redislocation rates per follow-up year. They did not find a significant difference in the redislocation frequency among the cylinder cast, splint and brace groups. In contrast, they showed that patients treated with a brace exhibited a significantly higher redislocation frequency per follow-up year. This effect might be due to the shorter immobilisation time in the brace group compared to the other groups. Another explanation might be found in the type of brace used: simple straps and knee sleeves. These days knee braces that maintain better patellar alignment are available.

Mäenpää et al. showed the highest frequency of knee joint restriction in patients treated with cylinder casts. However, the difference to the other groups was not significant. This might be the result of the limitation of joint movement caused by the cylinder cast, which might protect against redislocation but may cause degenerative changes in the bone, cartilage and knee ligaments. Moreover, this movement limitation might also be caused by the longer immobilisation time in the cylinder cast group compared to the splint and brace 
Table 2 Study results

\begin{tabular}{|c|c|c|c|c|c|}
\hline \multirow[b]{2}{*}{ Study, year } & \multicolumn{2}{|l|}{ Conservative treatment } & \multicolumn{2}{|l|}{ Comparison } & \multirow{2}{*}{$\begin{array}{l}p- \\
\text { value }\end{array}$} \\
\hline & Method $(n)$ & Redislocation $n(\%)$ & Method $(n)$ & Redislocation $n$ (\%) & \\
\hline Apostolovic, 2011 & Not specified (23) & $1(4)$ & Surgery (14) & $2(14)$ & Ns \\
\hline Bitar, 2012 & Brace (20) & $7(35)$ & Surgery (210) & $0(0)$ & $\mathrm{Nm}$ \\
\hline Buchner, 2005 & Brace (63) & $17(27)$ & Surgery (37) & $10(27)$ & Ns \\
\hline Camanho, 2009 & Splint (16) & $8(50)$ & Surgery (17) & $0(0)$ & $\mathrm{Nm}$ \\
\hline \multirow[t]{4}{*}{ Cash, 1988} & Group 1 & & & & \\
\hline & Splint (54) & $23(43)$ & Surgery (15) & $2(13)$ & $\mathrm{Nm}$ \\
\hline & Group 2 & & & & \\
\hline & Splint (20) & $4(20)$ & Surgery (14) & $1(7)$ & $\mathrm{Nm}$ \\
\hline Christiansen, 2008 & Brace (35) & $7(20)$ & Surgery (42) & $7(17)$ & Ns \\
\hline Cofield, 1977 & Not specified (35) & $11(31)$ & Surgery (13) & $0(0)$ & $\mathrm{Nm}$ \\
\hline Hawkins, 1986 & Not specified (20) & $3(15)$ & Surgery (7) & $0(0)$ & $\mathrm{Nm}$ \\
\hline Hing ${ }^{\#}, 2012$ & Not specified (157) & $53(34)$ & Surgery 182 & $47(37)$ & 0.26 \\
\hline Mäenpää, 1997 & Cylinder cast (60) & $23(38)$ & Splint (17) Brace (23) & $8(53) 13(48)$ & Ns \\
\hline Palmu*, 2008 & Brace (28) & $15(54)$ & Surgery (36) & $18(50)$ & Ns \\
\hline Rood, 2012 & Cast (9) & $0(0)$ & Tape (9) & $0(0)$ & $\mathrm{Nm}$ \\
\hline Sillanpää, 2008 & Brace (35) & $8(23)$ & Surgery (26) & $5(19)$ & 0.84 \\
\hline Sillanpää, 2009 & Brace (21) & $6(29)$ & Surgery (17) & $0(0)$ & 0.02 \\
\hline Sillanpää, 2011 & Brace restricted ROM (13) & $3(23)$ & Brace free ROM (13) & $5(38)$ & Ns \\
\hline
\end{tabular}

"Cochrane Review.

${ }^{*}$ Children and adolescents; Nm: not mentioned; Ns: not significant; ROM: range of motion.

Group 1: congenital abnormality extensor mechanism opposite knee.

Group 2: patients with normal opposite knee on examination.

groups. The lack of standardisation of the immobilisation time between groups in the Mäenpää et al. study makes the results unconvincing. Therefore, to find the most appropriate treatment for patellar dislocation, special attention should be given to the immobilisation time.

Although the above-mentioned study represents the best available evidence, the evidence level remains low because of the small study population, difference in immobilisation duration between groups, use of old braces and limitations in the study design.

Furthermore, 11 out of 12 studies comparing surgical and conservative treatment did not report significantly different redislocation rates $[3-11,13,15,16]$. In conformation with these results, a recently published Cochrane review based on five studies involving 339 participants did not find evidence of lower redislocation rates in patients who were managed with surgical repair compared with those who were managed with conservative treatment [11].

\section{Conclusion}

Based on the best available evidence, the treatment for primary acute patellar dislocation remains controversial. A posterior splint might be the best therapeutic option because of the low redislocation rates and knee joint restrictions. However, this recommendation is based on only one small study with significant limitations. Further investigation with modern braces and standardisation of immobilisation time is needed to find the most appropriate conservative treatment for patellar dislocation.

Furthermore, there is insufficient evidence to confirm the added value of surgical management.

Table 3 Study results: Mäenpää et al. 1997

\begin{tabular}{|c|c|c|c|c|c|c|c|c|}
\hline \multirow{2}{*}{$\begin{array}{l}\text { Treatment arm } \\
(n)\end{array}$} & \multicolumn{2}{|c|}{ Redislocation } & \multirow{2}{*}{\multicolumn{2}{|c|}{ Redislocation/years }} & \multicolumn{2}{|c|}{ Loss of extension } & \multicolumn{2}{|c|}{ Loss of flexion } \\
\hline & $(\%)$ & RR (Cl 95\%) & & & (\%) & RR (Cl 95\%) & $(\%)$ & RR (Cl 95\%) \\
\hline Cylinder cast (60) & 38 & & 0.12 & & 15 & & 27 & \\
\hline Posterior splint (17) & 47 & $1.2(0.68-2.23)$ & 0.08 & $\mathrm{Nm}$ & 6 & $0.39(0.05-2.89)$ & 6 & $0.22(0.03-1.55)$ \\
\hline Brace (23) & 57 & $1.5(0.91-2.39)$ & 0.29 & $<0.05$ & 13 & $0.87(0.26-2.93)$ & 17 & $0.65(0.24-1.74)$ \\
\hline
\end{tabular}

$R R$, relative risk; (Cl 95\%), 95\% confidence interval; $N m$, not mentioned. 


\section{Competing interests}

The authors declare that they have no competing interests.

\section{Authors' contributions}

All authors contributed to the research and the work presented in this paper. JPG: first author- conceived the research question, carried out the literature search, critical appraisal and data extraction, discussion and manuscript writing. LMV: second authors- carried out the literature search, critical appraisal, data extraction and participated in writing the manuscript. RAPAH: third author- supervised the developing of the research question, the discussion, and the manuscript writing. MIG: fourth author- primary supervisor. Coordinating the research project, supervising the discussion, manuscript writing and editing. All authors read and approved the final manuscript.

\section{Acknowledgements}

We thank Mendel van Griethuysen and Frank van Kemenade (plaster room, University Medical Center Utrecht) for making cylinder cast models for the images in this review. We thank Mr. Timmers (Medical Photographer, University Medical Center Utrecht) for producing accurate and objective images.

Received: 10 May 2012 Accepted: 20 November 2012

Published: 31 December 2012

\section{References}

1. Atkin DM, Fithian DC, Marangi KS, Stone ML, Dobson BE, Mendelsohn C: Characteristics of patients with primary acute lateral patellar dislocation and their recovery within the first 6 months of injury. Am J Sports Med 2000, 28:472-479.

2. Fithian DC, Paxton EW, Stone ML, Silva P, Davis DK, Elias DA, White LM: Epidemiology and natural history of acute patellar dislocation. Am J Sports Med 2004, 32:1114-1121.

3. Cash JD, Hughston JC: Treatment of acute patellar dislocation. Am J Sports Med 1988, 16:244-249.

4. Apostolovic M, Vukomanovic B, Slavkovic N, Vuckovic V, Vukcevic M, Djuricic G, Kocev N: Acute patellar dislocation in adolescents: operative versus nonoperative treatment. Int Orthop 2011, 35:1483-1487.

5. Bitar AC, Demange MK, D'Elia CO, Camanho GL: Traumatic patellar dislocation: Nonoperative treatment compared with MPFL reconstruction using patellar tendon. The American Journal of Sports Medicine 2012, 40:114-122.

6. Buchner M, Baudendistel B, Sabo D, Schmitt H: Acute traumatic primary patellar dislocation: long-term results comparing conservative and surgical treatment. Clin J Sport Med 2005, 15:62-66.

7. Camanho GL, Viegas Ade C, Bitar AC, Demange MK, Hernandez AJ: Conservative versus surgical treatment for repair of the medial patellofemoral ligament in acute dislocations of the patella. Arthroscopy 2009, 25:620-625.

8. Christiansen SE, Jakobsen BW, Lund B, Lind M: Isolated repair of the medial patellofemoral ligament in primary dislocation of the patella: a prospective randomized study. Arthroscopy 2008, 24:881-887.

9. Cofield RH, Bryan RS: Acute dislocation of the patella: results of conservative treatment. J Trauma 1977, 17:526-531.

10. Hawkins RJ, Bell RH, Anisette G: Acute patellar dislocations. The natural history. Am J Sports Med 1986, 14:117-120.

11. Hing CB, Smith TO, Donell S, Song F: Surgical versus non-surgical interventions for treating patellar dislocation. Cochrane Database Syst Rev 2011, 9:CD008106

12. Mäenpää H, Lehto MU: Patellar dislocation. The long-term results of nonoperative management in 100 patients. Am J Sports Med 1997, 25:213-217.

13. Palmu S, Kallio PE, Donell ST, Helenius I, Nietosvaara Y: Acute patellar dislocation in children and adolescents: a randomized clinical trial. $J$ Bone Joint Surg Am 2008, 90:463-470.

14. Rood A, Boons H, Ploegmakers J, van der Stappen W, Koëter S: Tape versus cast for non-operative treatment of primary patellar dislocation: a randomized controlled trial. Arch Orthop Trauma Surg 2012, 132:1199-1203.

15. Sillanpää PJ, Mäenpää HM, Mattila VM, Visuri T, Pihlajamäki H: Arthroscopic surgery for primary traumatic patellar dislocation: a prospective, nonrandomized study comparing patients treated with and without acute arthroscopic stabilization with a median 7-year follow-up. Am J Sports Med 2008, 36:2301-2309.

16. Sillanpää PJ, Mattila VM, Mäenpää H, Kiuru M, Visuri T, Pihlajamäki H: Treatment with and without initial stabilizing surgery for primary traumatic patellar dislocation. A prospective randomized study. J Bone Joint Surg Am 2009, 91:263-273.

17. Sillanpaa PJ, Maenpaa HM, Paakkala A: A prospective randomized study comparing non-operative treatment with and without knee immobilization for primary traumatic patellar dislocation. Arthroscopy - $J$ Arthroscopic Relat Surg 2011, 27:e183-e184.

doi:10.1186/1865-1380-5-45

Cite this article as: van Gemert et al.: Patellar dislocation: cylinder cast, splint or brace? An evidence-based review of the literature. International Journal of Emergency Medicine 2012 5:45.

\section{Submit your manuscript to a SpringerOpen ${ }^{\odot}$ journal and benefit from:}

- Convenient online submission

- Rigorous peer review

- Immediate publication on acceptance

- Open access: articles freely available online

- High visibility within the field

- Retaining the copyright to your article

Submit your next manuscript at $>$ springeropen.com 